\title{
DIAGNÓSTICO DE BRUCELOSE EM BOVINOS NO ABATEDOURO MUNICIPAL DE IMPERATRIZ-MA
}

\author{
Fernanda da Silva Martinho'; Ferdiman Gomes de Sousa Junior²; Dorival Sipião da Silva \\ Junior'²; Micael Ferreira dos Santos²; Wanderson Marques Gomes²; Leônidas Antônio Chow \\ Castillo ${ }^{3}$.

\footnotetext{
${ }^{1}$ Aluna de graduação do curso de Medicina Veterinária da Universidade Estadual do Maranhão, fehvet@hotmail.com ${ }^{2}$ Aluno de graduação do curso de Medicina Veterinária na Universidade Estadual do Maranhão
} \\ ${ }^{3}$ Professor da disciplina de patologia especial no curso de Medicina Veterinária, Universidade Estadual do Maranhão
}

RESUMO: Através de análise dos registros de animais abatidos no abatedouro municipal de Imperatriz-Ma, estudou-se os dados de 39.955 animais, e constatou-se que 0,03\% dos animais tiveram a carcaça descartada e incinerada devido à contaminação por Brucela abortus, agente etiológico da brucelose, uma zoonose das mais graves constatadas no país. O resultado obtido foi satisfatório demonstrando assim o eficaz programa de controle contra brucelose realizado na região.

PALAVRAS CHAVE: análise, controle, descartados, zoonose.

\section{DIAGNOSIS BRUCELLOSIS IN CATTLE SLAUGHTER IN MUNICIPAL ABATTOIR OF IMPERATRIZ-MA}

\begin{abstract}
Through analysis of records of animals slaughtered and disposed of the municipal abattoir Imperatriz-MA we studied data from 39,955 animals slaughtered for consumption, and it was found that $0.03 \%$ of the animals were discarded and the carcass incinerated due to contamination by Brucella abortus etiologic agent of brucellosis, one of the most serious zoonotic disease found in the country. The result was satisfactory thus demonstrating the effective control program against brucellosis carried out in the region.
\end{abstract}

KEY-WORDS: analysis, control, disposed, zoonosis.

\section{INTRODUÇÃO}

A introdução de materiais genéticos, $o$ crescimento desordenado dos rebanhos e a precariedade ou falta de manejo sanitário, facilitou a disseminação de doenças. Dentre todas elas destacamos a brucelose bovina (BEER, 1999).

A brucelose é uma enfermidade infecciosa causada por um cocobacilus gramnegativo, pequeno e pleomórfico chamado Bucella abortus (ROBBINS, 1967). Sendo uma conhecida zoonose, de caráter endêmico no Brasil e de grande importância econômica.

A transmissão da brucelose entre bovinos ocorre por via oral e genital. No campo, o abortamento e outros problemas da reprodução são presuntivos da doença, o diagnóstico sorológico o definitivo. Muitas vezes no animal apresenta-se de forma assintomática transformando-se em fonte de infecção para outros animais. No abate, lesões de bolsas serosas denominadas bursites têm 
sido associadas com infecção brucélica (LOPES, 2008)

Nos humanos a infecção na maioria das vezes se dá oralmente, através da ingestão de alimentos contaminados, carne e leite, ou pode ocorrer através do contato direto com o material infeccioso. O controle sanitário em abatedouros deve ser necessariamente rigoroso, para que se evite a proliferação da doença, pois uma carcaça contaminada quando destinada a consumo, virá a ser consumida por dezenas de pessoas.

O diagnostico positivo para brucelose se dá quando carcaças apresentam lesões imputáveis à brucelose. (Lei no 1.283 Art. 163 RIISPOA, 1950). Devido a difícil percepção das lesões com o animal ainda em vida, é no exame pos-morte, realizado pelo serviço de inspeção do abatedouro, que macroscopicamente são identificadas às lesões em formato de bursa que contem material purulento e infeccioso em seu interior. Nos casos de lesões localizadas encaminham-se as carcaças à esterilização pelo calor, depois de removidas e condenadas (Lei n ${ }^{\circ} 1.283$ Art. 163 RIISPOA, 1950).

O número de carcaças condenadas logo após o abate devido à contaminação por Brucella abortus ainda é um considerável causador de prejuízos econômicos. O presente trabalho dedica-se ao estudo do número de casos positivos de brucelose no abatedouro municipal de Imperatriz-MA.

\section{MATERIAL E METODOS}

O material constou de 39.955 exames, procedentes de bovinos abatidos no abatedouro municipal de Imperatriz, arquivados no banco de dados da Agencia de Defesa Agropecuária do Maranhão - AGED MA.

Os exames foram organizados em planinhas do programa microsoft ofice Excel 2003, no período de 02 a 05 de junho de 2011 e procedida a pesquisa na data posterior. Após analisados os dados foi calculada a taxa de incidência. Um estudo longitudinal do tipo estudo de corte com resultado em percentual. A incidência diz respeito ao número de novos casos de um determinado resultado de saúde num espaço de tempo definido (AGUIAR, 2007).

\section{RESULTADOS E DISCUSSÃO}

Como a brucelose é uma patologia de fácil disseminação, o controle deve ser iniciado nas propriedades e finalizado nos abatedouros ou frigoríficos, onde o mesmo deve ser rigoroso e eficaz, pois afeta os produtores, funcionários responsáveis pelo manejo do animal na fazenda, operários do abatedouro, açougueiros e por fim o consumidor (LOPES, 2008). Os resultados foram apresentados na tabela abaixo: 
Tabela 1. Total de carcaças descartadas devido à infecção por Brucela abortus no matadouro municipal de Imperatriz-MA, classificados quanto à origem.

\begin{tabular}{lcc}
\hline Município & $\mathrm{N}^{\mathrm{o}}$ de casos & $\%$ \\
\hline Amarante - MA & 4 & $0,01 \%$ \\
João Lisboa - MA & 1 & $0,002 \%$ \\
Montes Altos - MA & 2 & $0,005 \%$ \\
Senador La Roque - MA & 5 & $0,014 \%$ \\
Vila Nova dos Martírios - MA & 1 & $0,002 \%$ \\
\hline Total & 13 & $0,03 \%$ \\
\hline
\end{tabular}

A brucelose é uma zoonose das mais graves em nosso país, os inquéritos efetuados com referência a brucelose humana, são na grande maioria em pessoas que trabalham em matadouros (PACHECO E MELO, 1952). O percentual de animais, descartados e incinerados no abatedouro municipal de Imperatriz-MA devido à infecção por Brucela abortus é baixo e mostra o eficaz programa de controle realizado pela agencia de defesa agropecuária da região.

\section{CONCLUSÕES}

Dos 39.955 exames analisados 13 apresentavam resultado positivo de brucelose.

Conforme o resultado obtido constatou-se que o abatedouro municipal de Imperatriz, apesar de apresentar baixo percentual de carcaças condenadas, é fonte de infecção de brucelose para a espécie humana, havendo a necessidade do uso de equipamentos de proteção individual pelos funcionários, e rigorosa inspeção sanitária no local.

\section{REFERÊNCIAS}

AGUIAR, Pedro. Ficha formativa de estatística, São Paulo: Eurotrials Scientific Consultants, 2007.

ALMEIDA, L. P. Brucelose em bovinos com bursite cervical diagnosticada em abatedouro sob inspeção federal. Revista ciênca rural, Rio Grande do Sul, v. 30, n. 2, 2000.

BEER, J. Doenças infecciosas em animais domésticos, São Paulo: Rocca, 1999. p. 162 169.

LOPES, C. A. R. Prevalência de brucelose e tuberculose em bovinos abatidos sob inspeção estadual no município de Aracruz - ES, Espírito Santo: Qualitas Instituto de pós graduação, 2008. 
MINISTÉRIO DA AGRICULTURA. ROBINS, S. L. Tatado de patologia, Regulamento da inspeção industrial e México: Editorial interamericana S.A. 1968. sanitária de produtos de origem animal - $\quad$ p. $295-296$.

RIISPOA. Legislação básica do ministério da agricultura Lei ${ }^{\circ} 1.283$ de 18 de dezembro de 1950.

PACHECO E MELLO, M. T. Brucelose humana em operários de um frigorífico no município de Salvador, Bahia Brasil. Rev. Saúde Pública, São Paulo, v. 6, n. 2, 1972. 